\title{
Pembentukan Data Mart Menggunakan Metode Generalization
}

\author{
I Gede Sugita Aryandana ${ }^{\mathrm{a} 1}$, I Made Sukarsa ${ }^{\mathrm{a} 2}$, Putu Wira Buana ${ }^{\mathrm{a} 3}$ \\ aJurusan Teknologi Informasi, Fakultas Teknik, Universitas Udayana \\ Jalan Kampus Bukit Jimbaran, Bali, Indonesia \\ 1sugitaaryandana@gmail.com \\ 2sukarsa@gmail.com \\ 3wbhuana@gmail.com
}

\begin{abstract}
Abstrak
Teknologi zaman sekarang menyebabkan kebutuhan data suatu instansi atau perusahaan untuk mengolah data atau menganalisis data secara cepat, padat dan semakin tinggi. Perusahaan atau instansi menginginkan proses analisa data dapat menghemat waktu sebanyak-banyaknya. Data warehouse merupakan sebuah teknologi analisis data yang berguna untuk mengatasi masalah tersebut. Data warehouse merupakan gudang data yang berguna untuk menampung semua history data yang dimiliki oleh instansi atau perusahaan. Data mari merupakan bagian kecil dari data warehouse. Datamart difokuskan pada satu subjek. Penelitian ini menggunakan Metode Generalization untuk melakukan proses pembentukan datamart. Generalization merupakan sebuah metode yang berguna untuk memperkecil atau mempersempit perbedaan data berdasarkan Subclass. Subclass tersebut disatukan menjadi sebuah Superclass yang berguna untuk menampung beberapa data dari Subclass. Subclass merupakan data yang sifatnya lebih deskriptif. Superclass merupakan data sifatnya lebih general. Hasil yang didapatkan adalah kumpulan dari beberapa Subclass yang telah ditentukan atau dipilih kemudian membentuk sebuah Superclass yang berguna untuk menampung sumber informasi dari Subclass.
\end{abstract}

Kata Kunci: Data Warehouse, Data Mart Generalization.

\begin{abstract}
Technology today causing the data needs of an agency or company to process the data or analyze data quickly, dense and higher. Companies or institutions want the data analysis process can save time as much as possible. The data warehouse is a data analysis technology that is useful to resolve the issue. The data warehouse is a repository of data that is useful to accommodate all the history data held by agencies or companies. Data marts are small part of the data warehouse. Data mart is focused on a single subject. This study uses a generalization method to perform the process of establishing a data mart. Generalization is a useful method to reduce or narrow the differences in the data based Subclass. Subclass were integrated into a Superclass useful to collect some data from the Subclass. Subclass is the data that is more descriptive. Superclass is more general in nature of data. The result obtained is a collection of some Subclass predetermined or selected later formed a Superclass useful to accommodate the resources of the Subclass.
\end{abstract}

Keywords: Data Warehouse, Data Mart Generalization.

\section{Pendahuluan}

Berkembangnya teknologi pada zaman sekarang menyebabkan kebutuhan masyarakat untuk memperoleh data dan menyimpan data menjadi cukup besar dan tinggi. Penyimpanan data yang sangat besar membuat instansi atau perusahaan melakukan pengolahan data yang efisien dan efektif. Data warehouse merupakan teknologi yang dapat mengatasi masalah tersebut. Teknologi data warehouse berguna untuk menggabungkan data dari setiap cabang 
perusahaan atau instansi di berbagai daerah yang berbeda. Pengukuran kinerja oleh perusahaan atau instansi tersebut berguna untuk mengetahui pertumbuhan data yang dialami oleh perusahaan atau instansi yang terkait [1]. Database lebih bersifat data yang melakukan proses sistem sedangkan data warehouse lebih bertugas untuk melakukan analisa data atau read only pada suatu sistem kegunaannya yaitu untuk mengambil keputusan dan melakukan analisa data yang telah ada.

Data warehouse sangat berbeda dengan database. Data warehouse memiliki arsitektur yang lebih jelas. Data warehouse sudah melewati tahap normalisasi dan database belum melewati tahap normalisasi, sehingga data yang ada di dalam data warehouse menjadi lebih terorganisir dan terbentuklah suatu data mart di dalam data warehouse [2].

Penelitian "Pembentukan Data Mart menggunakan Generalization" merupakan penelitian yang berguna untuk meminimalisir perbedaan data atau memperkecil perbedaan data dengan Subclass dan Superclass [3]. Subclass mempunyai sifat data yang deskriptif sedangkan Superclass mempunyai sifat data yang lebih umum, dengan adanya pembeda data yaitu Subclass dan Superclass diharapkan dapat memudahkan dalam mengambil keputusan dan analisa data. Penelitian dikembangkan untuk memberikan efisiensi data dan memudahkan organisasi dalam membedakan data dan melakukan pembentukan data mart.

Menurut Hajer Baazaoui Zha, Sami Faiz, Henda Ben Ghezela, di dalam penelitian yang berjudul "CASME: A CASE Tool for Spatial Data marts Design and Generation" generalization merupakan data yang bersifat spasial dan non spasial. Data spasial merupakan data yang masih bersifat deskriptif, di dalam penelitian tersebut terdapat dua contoh data yang dibahas yaitu gelar sarjana dan diploma. Data non spasial merupakan data yang bersifat general yang artinya beberapa data spasial dapat diwakili dengan data non spasial [4].penelitian tersebut akan memberikan pengguna berupa informasi berdasarkan wilayah yang dipilih kemudian di dalam wilayah tersebut terdapat data yang bersifat lebih deskriptif. Penelitian tersebut membahas mengenai sistem informasi geografis yang menggunakan metode Generalization untuk menentukan informasi berdasarkan wilayah yang dipilih. Persamaan penelitian Hajer Baazaoui Zghal, Sami Faiz, Henda Ben Ghezela dengan penelitian ini yaitu membahas data yang bersifat general dapat memberikan semua informasi yang terkait.

Menurut penelitian Yoann Pitarch, Cécile Favre, dan Anne Laurent, di dalam penelitian yang berjudul "Context Aware Generalization for Cube Measures" membahas mengenai hierarki data yang sangat penting untuk mendapatkan analisa data yang akurat. Data hierarki yang dimaksud adalah adanya hubungan data satu dengan yang lain, hampir menyerupai pohon faktor dengan saling berkaitan. Data yang saling berkaitan diharapkan nantinya ketika melakukan analisa dapat mengetahui hubungan data yang saling terkait. Keterkaitan data dapat memudahkan untuk melakukan analisa menjadi lebih baik [5]. Memudahkan dalam melakukan analisa data dan mencari sumber data dari hierarki yang telah dibuat. Persamaan dengan penelitian Yoann Pitarch, Cécile Fari, dan Anne Laurent (2010) dan penelitian ini adalah mencari keterkaitan data yang bersifat deskriptif dengan data yang bersifat general menjadi acuannya.

Menurut penelitian Ran Liu, Kenneth R. Koedinger, Elizabeth A. McLaughlin, di dalam penelitian yang berisi mengenai "Interpreting Model Discovery and Testing Generalization to a New Dataset" membahas mengenai algoritma Learning Factors Analysis (LFA) yang berguna untuk menerjemahkan bahasa yang mudah dimengerti oleh mesin agar ketika pengguna memasukkan sebuah perintah, mesin agar cepat mengerti dan mengeluarkan hasil sesuai dengan perintah. Algoritma Learning Factors Analysis (LFA) mulai berkembang sejak 19961997 perkembangan yang dialami oleh algoritma Learning Factors Analysis (LFA) membuat para pengembang untuk membuat sebuah teknologi yang dimengerti oleh mesin. Kegunaan dari algoritma Learning Factors untuk melakukan analisa informasi yang ada [6]. Procedure yang dilakukan oleh algoritma LFA sebenarnya mirip dengan metode Generalization yaitu mesin mulai mengumpulkan bahasa yang dianggap sama, kemudian mesin mulai merangkum setiap perintah yang diinputkan. Mesin akan menyaring setiap perintah yang telah dilakukan oleh pengguna tujuannya yaitu untuk mendapatkan hasil yang diinginkan oleh pengguna. Mesin membutuhkan proses pengecekan atau lopek untuk memastikan perintah yang diinputkan apakah ada atau tidak. 


\section{Metodologi Penelitian}

Pembentukan Data Mart menggunakan metode Generalization menggunakan metode penelitian yaitu Metode Waterfall. Metode Waterfall memiliki beberapa tahapan, yaitu analisis, desain, implementasi, pengujian, dan pemeliharaan. Tahap analisis merupakan tahapan untuk mengetahui kebutuhan data yang digunakan. Tahap implementasi merupakan tahapan yang melakukan konversi dari bahasa pemrograman menjadi bahasa yang dimengerti oleh komputer. Tahap pengujian merupakan tahapan untuk melakukan testing apakah sesuai dengan prosedur atau rancangan yang sudah diperkirakan. Tahap pemelihara merupakan tahapan untuk menjaga kondisi aplikasi, agar dapat digunakan dalam jangka panjang.

\subsection{Gambaran Umum}

Gambaran umum dari Pembentukan Data Mart menggunakan metode Generalization ditunjukkan pada Gambar 1.

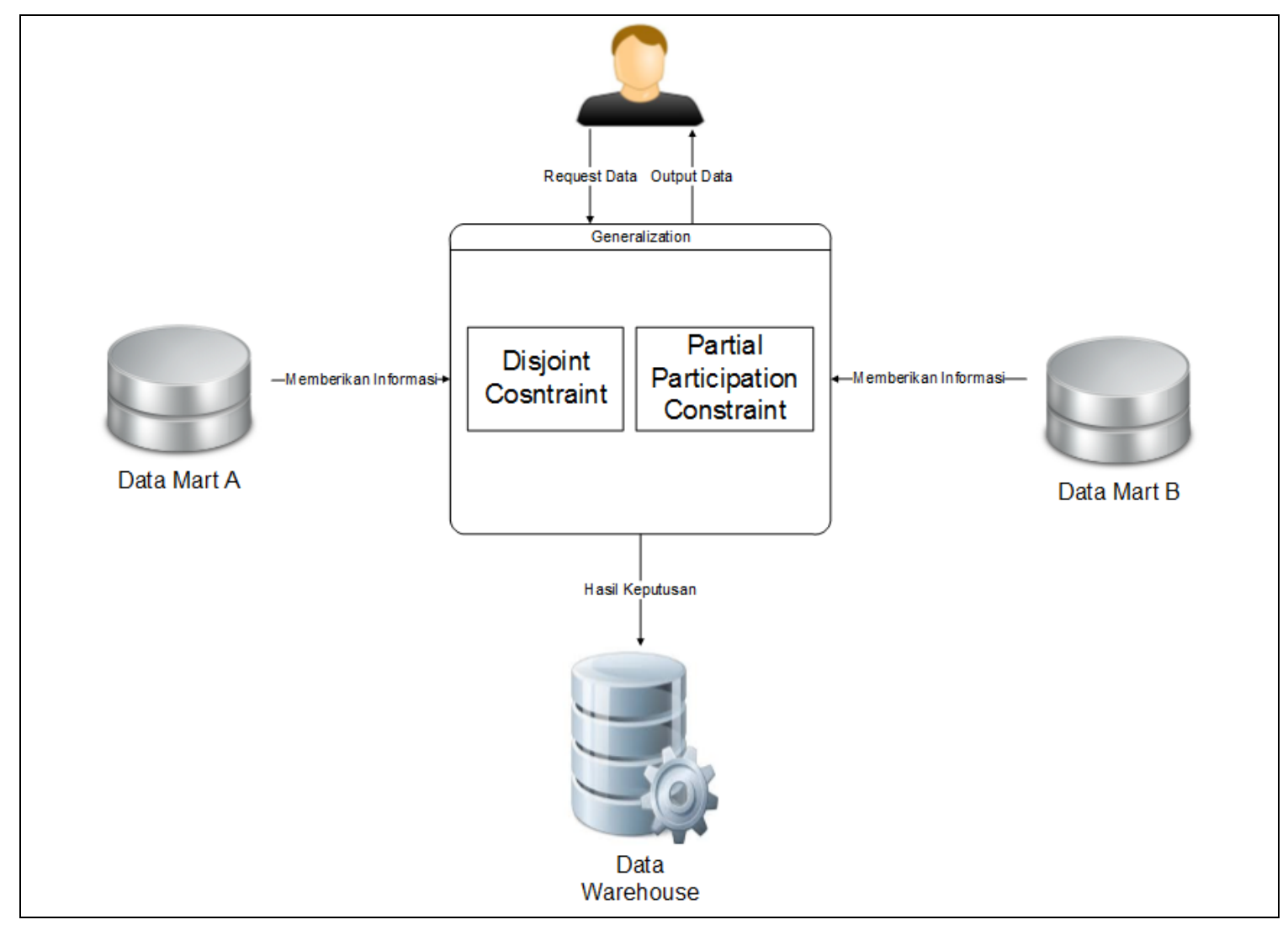

Gambar 1. Gambaran Umum

Tahapan dari gambaran umum sistem pada Gambar 1 yaitu administrator melakukan akses ke sistem dengan memasukkan hostname atau IP Address yang telah dibuat. Tahap kedua setelah administrator memasukkan hostname atau ip address, administrator dapat mengakses data mart yang berasal dari hostname atau ip address tersebut. Tahap ketiga administrator harus menentukan relasi atau hubungan antar Subclass agar superclass dapat terbentuk. Tahap keempat administrator melakukan tahap mapiku data mart, mapping tabel, dan mapping field untuk membentuk sebuah Superclass. tahap kelima administrator mempunyai sebuah Superclass yang berguna untuk mengetahui asal tabel dan mengetahui hubungan dari sumber data yang telah di-mapping.

\subsection{Metodologi Mapping}

Metodologi Mapping digunakan untuk mengetahui tahapan yang terjadi dalam Pembentukan Data Mart menggunakan Metode Generalization. 


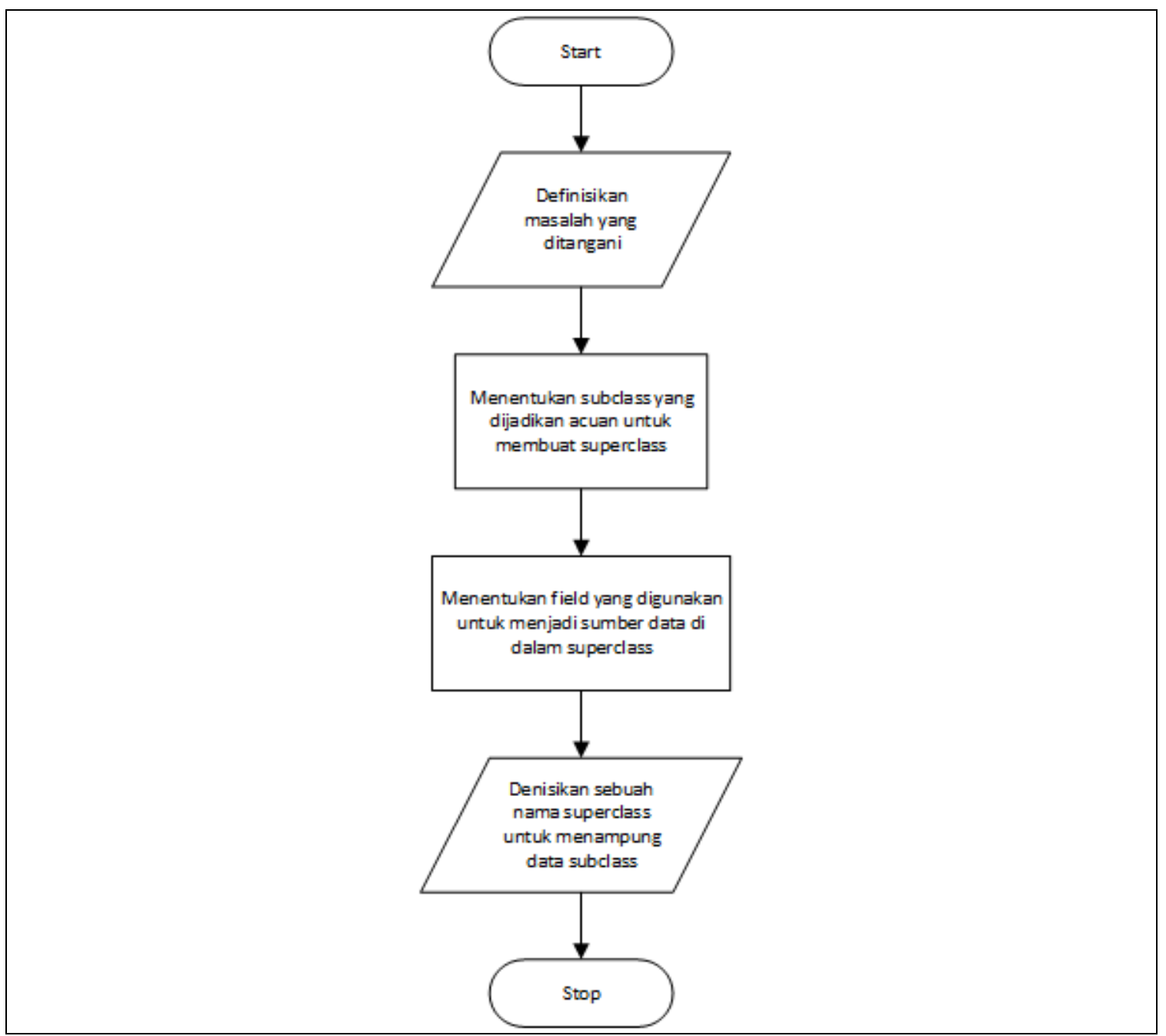

Gambar 2. Alur Mapping Generalization

Alur penelitian merupakan bagan atau flowchart yang menggambarkan proses arus mapping dalam perancangan Pembentukan Data Mart menggunakan Metode Generalization. Tahapannya adalah sebagai berikut.

a. mendefinisikan masalah yang ditangani

b. menentukan Subclass yang digunakan sebagai acuan untuk membentuk superclass

c. menentukan field berguna sebagai informasi atau pembeda di dalam superclass

d. mendefinisikan sebuah nama superclass yang menampun data dari Subclass.

\section{Kajian Pustaka}

Kajian pustaka digunakan untuk menunjang materi dalam pembuatan penelitian Pembentukan Data Mart menggunakan Metode Generalization.

\subsection{Data Warehouse}

Data Warehouse adalah sebuah gudang data yang berguna untuk melakukan penyimpanan data atau menampung data dalam skala yang lebih besar. Ruang lingkup dalam data warehouse yaitu sebuah instansi atau perusahaan yang mempunyai sumber data dalam bentuk yang lebih besar. Kegunaan dari data warehouse untuk melakukan analisis di dalam perusahaan [7]. Data warehouse juga bisa disebut sebagai penyimpanan media elektronik yang jumlahnya sangat besar yang berisi mengenai informasi perusahaan atau instansi. 
Penyimpanan data warehouse harus aman, dan mudah digunakan yang dalam arti perusahaan bisa mengelola data yang sudah menjadi data warehouse.

\subsection{Data Mart}

Data mart adalah bentuk sederhana dari data warehouse yang difokuskan pada satu subjek (fungsional) seperti marketing dan keuangan. Data mart sering dibangun dan dikendalikan oleh satu departemen dalam sebuah organisasi. Data mart biasanya menarik data dari beberapa sumber yang dianggap penting di dalam suatu perusahaan. Sumber data yang diambil oleh data mart biasanya dari sumber data internal operasional, data warehouse pusat, atau data eksternal [8]. Data warehouse hampir mirip dengan data mart, bedanya terletak bagian data yang diukur, data warehouse mengukur semua jenis data sedangkan data mart mengukur beberapa jenis data. Data mart lebih kecil dan lebih kompleks dari pada data warehouse. Perusahaan lebih mudah menggunakan data mart karena mereka lebih mengetahui sumber data yang dijadikan pengukuran.

\subsection{Generalization}

Metode Generalization adalah metode yang dapat mempersempit atau memperkecil perbedaan antar tabel dengan cara melakukan identifikasi terlebih dahulu di setiap tabel yang berbeda serta atribut yang dimiliki. Tujuannya agar menjadi satu tabel (Superclass), dengan membuat pengolahan data menjadi lebih efisien dan efektif dari segi waktu maupun penggunaannya. Dapat mewakili setiap informasi yang dimiliki oleh entitas tersebut [9]. Metode Generalization dapat dilakukan jika terdapat lebih dari satu entitas yang memiliki perbedaan informasi tetapi masih memiliki makna sama atau informasi yang sama. Generalization mempunyai konsep yang digunakan untuk menggabungkan Subclass menjadi superclass. Konsep generalization yang dimiliki adalah sebagai berikut:

a. Disjoint constraint merupakan proses yang memberikan informasi bahwa Subclass dari superclass merupakan anggota dari salah satu Subclass dengan memberikan huruf ' $d$ ' pada relasi tabel.

b. Participation constraint partial merupakan proses yang memberikan keterangan di dalam Superclass. Superclass merupakan anggota dari Subclass yang telah didefinisikan.

\section{Hasil Mapping Metode Generalization}

Hasil metode generalization merupakan hasil dari pembentukan beberapa Subclass menjadi sebuah superclass. Contoh dari hasil superclass adalah sebagai berikut.

\subsection{Langkah-langkah Mapping Generalization}

a. Langkah pertama tentukan Subclass yang ingin digabung ke dalam superclass beserta atribut yang ada di dalamnya termasuk primary key. Langkah selanjutnya yaitu memilih field yang dibutuhkan oleh superclass yang sumber datanya berasal dari Subclass. Tabel pegawai merupakan sebuah tabel yang mempunyai data bersifat deskriptif (Subclass), adapun contoh tabel pegawai adalah sebagai berikut.

Tabel 1. Pegawai

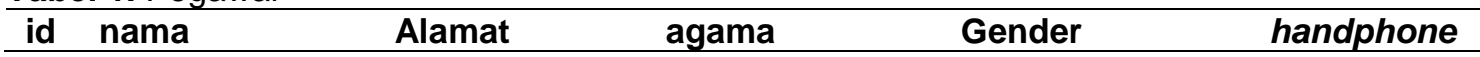

Tabel 1 menunjukkan tabel pegawai yang berguna untuk menjadi bagian dari tabel superclass pekerjaan dengan informasi berupa id, nama, alamat, agama, gender, alamat yang berasal dari tabel pegawai. Tabel 2 di bawah adalah contoh data atau gambaran data yang nantinya ada di dalam tabel pegawai.

Tabel 2. Contoh data pegawai

\begin{tabular}{llllll}
\hline id & nama & Alamat & agama & Gender & handphone \\
\hline 1 & gede & Denpasar & Hindu & Laki-laki & 123456789 \\
2 & yoga & Singaraja & Hindu & Laki-laki & 676767676 \\
3 & desak & Gianyar & Hindu & perempuan & 121212121 \\
\hline
\end{tabular}


Tabel dosen merupakan sebuah tabel yang mempunyai data bersifat (Subclass). Contoh data dari tabel dosen adalah sebagai berikut.

Tabel 3. Dosen

id nama Gelar gender type unique unique_id alamat

Tabel 3 menunjukkan tabel dosen yang berguna untuk menjadi bagian dari tabel superclass pekerjaan dengan informasi berupa id, nama, gelar, gender, type unique, alamat yang berasal dari tabel dosen. Tabel 4 di bawah adalah contoh data atau gambaran data yang nantinya ada di dalam tabel dosen.

Tabel 4. Contoh data dosen

\begin{tabular}{llllccc}
\hline id & nama & Gelar & gender & type unique & unique_id & alamat \\
\hline 1 & Navi & S2 & Laki-laki & NIP & 9908011 & Denpasar \\
2 & arta & S3 & Laki-laki & NIP & 9908201 & Tabanan \\
3 & gede & S2 & Laki-laki & NUPN & 9898989 & Bangli \\
\hline
\end{tabular}

Tabel superclass pekerjaan merupakan sebuah tabel gabungan dari tabel pegawai dan tabel dosen yang berguna untuk mewakili informasi kedua tabel. contoh tabel superclass pekerjaan adalah sebagai berikut.

Tabel 5. Superclass pekerjaan

ld_superclass $\quad$ Subclass_id $\quad$ Keterangan

Tabel 5 menunjukkan tabel Superclass pekerjaan yang berguna untuk menampung data dari tabel pegawai dan tabel dosen dengan menambahkan field khusus seperti id_superclass dan keterangan sebagai prototype. Tabel 6 di bawah adalah contoh data atau gambaran data yang nantinya ada di dalam tabel dosen.

Tabel 6. Contoh Data Superclass Pekerjaan

\begin{tabular}{lll}
\hline Id_superclass & Subclass_id & Keterangan \\
1 & 3 & Tabel dosen \\
2 & 1 & Tabel pegawai \\
\hline
\end{tabular}

b. Alur kerja yang kedua yaitu buatlah sebuah relasi terpisah yang sesuai dengan masingmasing entitas Subclass beserta atributnya. Primary key di masing-masing Subclass menjadi foreign di dalam tabel superclass pegawai yang berguna untuk mengetahui asal tabel dari Subclass. Aturan kedua dapat digunakan jika entitas superclass dan entitas Subclass memenuhi syarat dari modul disjoint constraint dan partial constraint. Contoh gambar dari alur kedua adalah sebagai berikut.

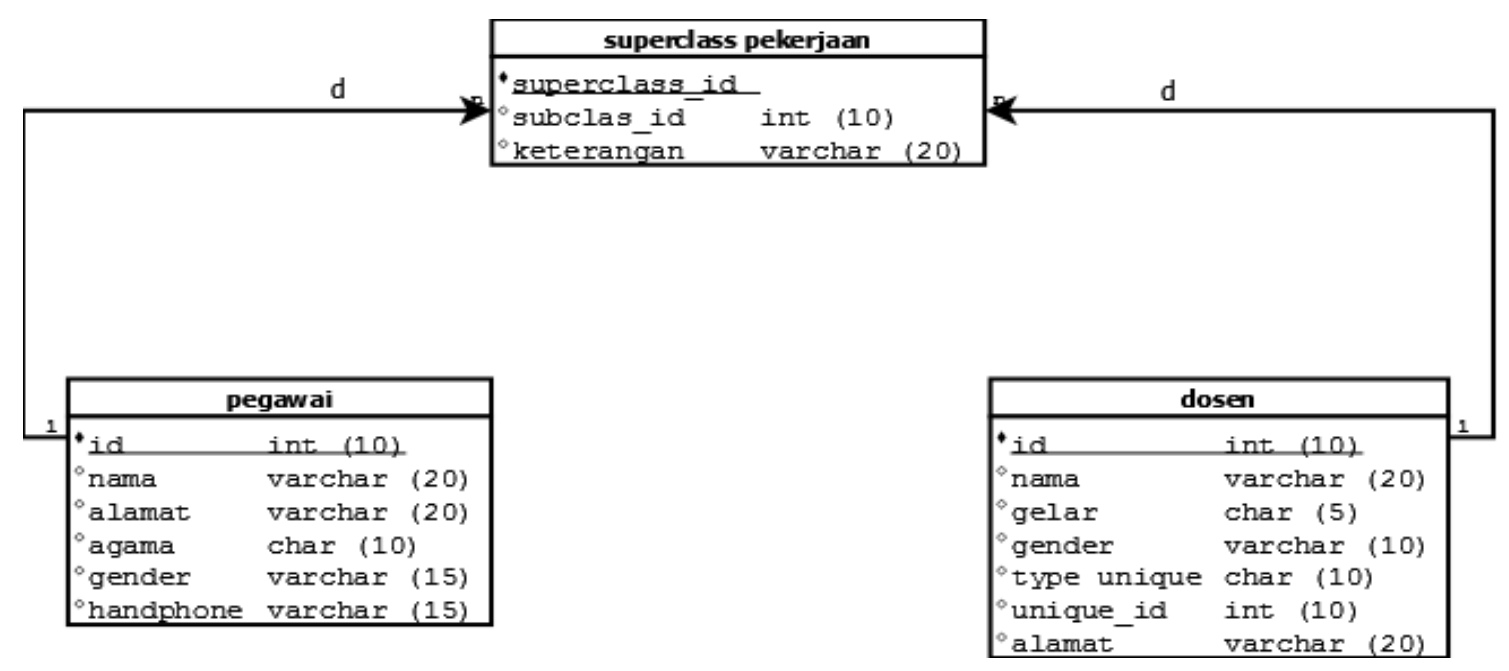

Gambar 3. Skema Generalization 
Gambar 3 menunjukkan hasil skema dari metode generalization. skema tersebut dapat terjadi dikarenakan adanya modul dari metode generalization yaitu disjoint constraint dan partial constraint. Pertama dimulai dari disjoint constraint, yaitu tabel superclass pekerjaan merupakan anggota dari tabel pegawai dan tabel dosen. Partial constraint yaitu Tabel Superclass pekerjaan dapat menjadi bagian dari tabel pegawai atau dapat menjadi tabel dosen.

c. Alur kerja yang ketiga yaitu membuat superclass yang berguna untuk mewakili informasi dari setiap Subclass. Superclass harus mempunyai semua atribut yang dimiliki oleh Subclass. Superclass juga harus mempunyai satu field yang berguna untuk membedakan setiap entitas Subclass, contoh dari alur ketiga adalah sebagai berikut.

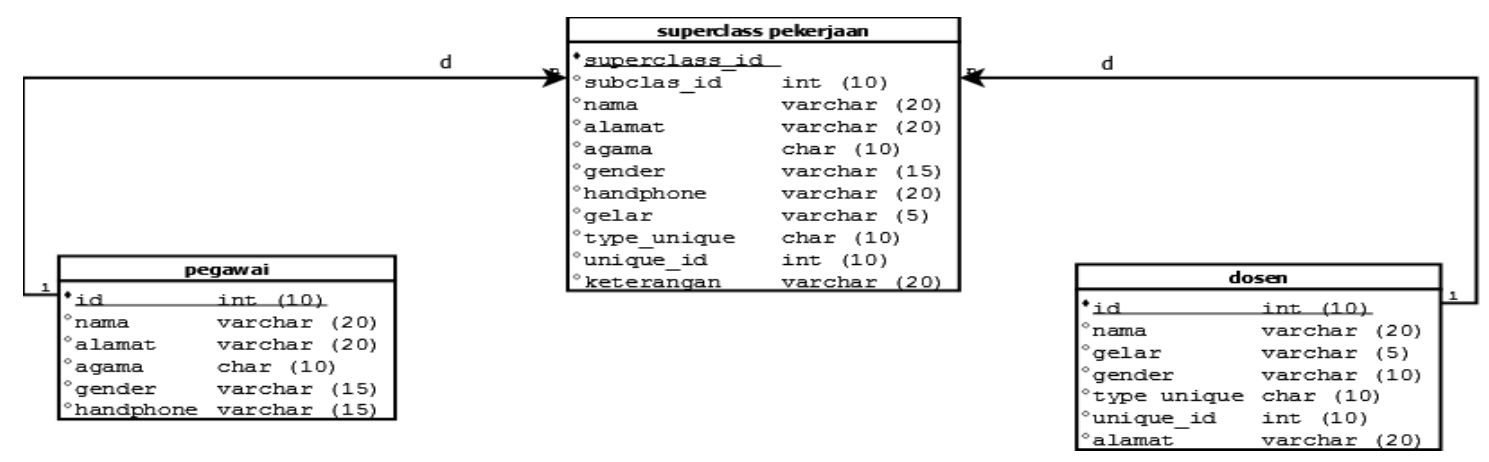

Gambar 4. Hasil Skema Generalization

Gambar 4 menunjukkan hasil mapping generalization dari struktur data yang berbeda-beda. Hasilnya adalah semua atribut yang dimiliki oleh tabel pegawai dan tabel dosen, harus ada di dalam tabel superclass pekerjaan yang berguna untuk mewakili setiap informasi yang dimiliki oleh kedua entitas tersebut. Tabel superclass pekerjaan merupakan gabungan dari beberapa atribut yang dimiliki oleh tabel pegawai (Subclass) dan tabel dosen (Subclass). Tabel superclass pekerjaan (superclass) memiliki satu field yang berguna untuk membedakan informasi dari tabel pegawai (Subclass) dan tabel dosen (Subclass). Field yang dimaksud adalah field keterangan yang berguna untuk memberikan definisi atau informasi kepada tabel pegawai (Subclass) dan tabel dosen (Subclass). Tujuannya yaitu untuk membedakan setiap data yang masuk di dalam tabel pekerjaan. Tabel 7 di bawah adalah contoh data atau gambaran data yang nantinya ada di dalam tabel superclass pekerjaan.

Tabel 7. Contoh Data Superclass Pekerjaan

\begin{tabular}{llllll}
\hline Superclass_id & Subclass_id & nama & alamat & agama & Gender \\
\hline 1 & 3 & gede & bangli & hindu & Laki-laki \\
2 & 1 & gede & denpasar & hindu & Laki-laki \\
\hline
\end{tabular}

\begin{tabular}{lllll}
\hline Handphone & gelar & Type_unique & Unique_id & keterangan \\
\hline- & S2 & NUPN & 9898989800 & Tabel dosen \\
123456789 & - & - & - & Tabel pegawai \\
\hline
\end{tabular}

Tabel 6 menunjukkan hasil dari mapping generalization dengan menggabungkan dua tabel yaitu tabel pegawai dengan menghasilkan satu field khusus yaitu field keterangan sebagai pembeda sumber data atau Subclass. Kegunaannya dari mapping generalization ini adalah untuk menggabungkan beberapa Subclass menjadi superclass sehingga menghasilkan data yang bersifat general dan lebih efisien dalam memberikan informasi.

\subsection{Analisis Hasil}

Analis hasil yang dilakukan dari penelitian ini adalah untuk mengetahui hasil mapping dari metode Generalization adalah sebagai berikut. 
a. Pegawai merupakan jabatan atau seseorang yang melaksanakan tugasnya untuk mendapatkan imbalan berupa uang atau gaji dan tunjangan yang diberikan oleh pemerintah.

b. Dosen merupakan ilmuan dengan tugas utama untuk memberikan ilmu pengetahuan atau menyebarluaskan ilmu pengetahuan, mengembangkan teknologi, melakukan penelitian.

\subsection{Hasil Analisa Menggunakan Jumlah Field Berbeda}

\begin{tabular}{|l|}
\hline Pilih Database \\
\hline db_dosen \\
Pilih Tabel \\
$\quad$ tb_dosen \\
\\
$\checkmark$ id \\
$\checkmark$ nama \\
$\checkmark$ gelar \\
$\checkmark$ type_unique \\
$\checkmark$ unique_id \\
$\checkmark$ alamat \\
\end{tabular}

Gambar 5. Subclass Dosen

Gambar 5 menunjukkan pemilihan Subclass atau data mart dosen dengan menggunakan tabel dosen sebagai acuan, serta ketujuh field yang dipilih digunakan untuk menganalisis data. Field yang digunakan dalam melakukan analisis data adalah id, nama, gelar, gender, type_unique, unique_id dan alamat. Field di atas dapat digunakan untuk menampung sumber data atau informasi yang dimiliki oleh Subclass db_dosen.

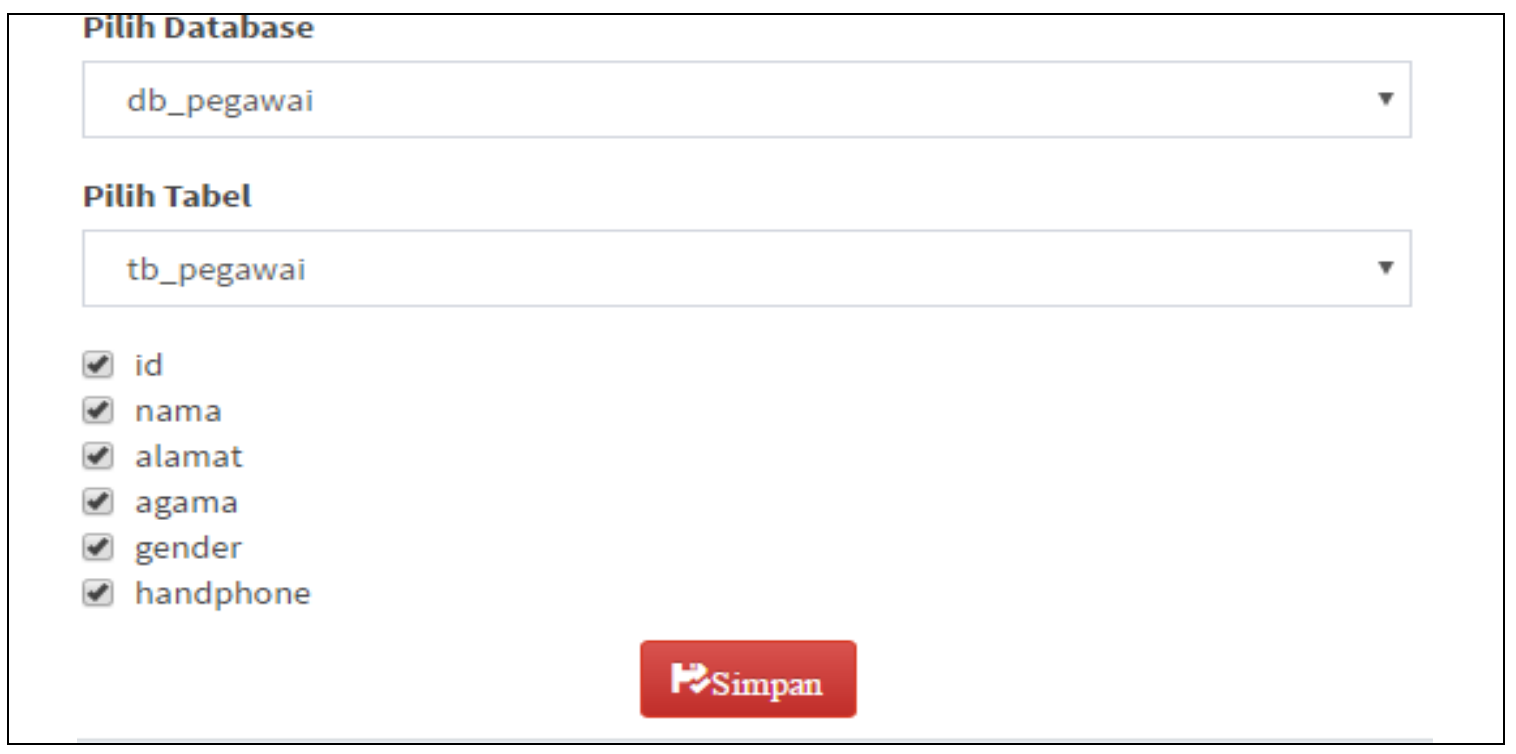

Gambar 6. Subclass Pegawai 


\subsection{Hasil Analisa Menggunakan Jumlah Field Sama}

\begin{tabular}{|l|}
\hline Pilih Database \\
db_dosen \\
Pilih Tabel \\
tb_dosen \\
\\
$\checkmark$ id nama \\
$\checkmark$ gelar \\
gender \\
type_unique \\
\\
\end{tabular}

Gambar 10. Subclass Dosen

Gambar 10 menunjukkan pemilihan Subclass atau data mart dosen dengan menggunakan tabel dosen sebagai acuan, serta keenam field yang dipilih digunakan untuk menganalisis data. Field yang digunakan dalam melakukan analisis data adalah id, nama, gelar, gender, type_unique, dan unique_id. Field di atas dapat digunakan untuk menampung sumber data atau informasi yang dimiliki oleh Subclass db_dosen.

\begin{tabular}{|c|c|c|}
\hline db_pegawai & & $\mathbf{v}$ \\
\hline \multicolumn{3}{|l|}{ Pilih Tabel } \\
\hline tb_pegawai & & $\boldsymbol{v}$ \\
\hline \multirow{6}{*}{$\begin{array}{l}\varpi \text { id } \\
- \text { nama } \\
- \text { alamat } \\
- \text { agama } \\
- \text { gender } \\
\varpi \text { handphone }\end{array}$} & & \\
\hline & & \\
\hline & & \\
\hline & & \\
\hline & & \\
\hline & Fsimpan & \\
\hline
\end{tabular}

Gambar 11. Subclass Pegawai

Gambar 11 menunjukkan pemilihan Subclass atau data mart pegawai dengan menggunakan tabel pegawai sebagai acuan, serta keenam field yang dipilih digunakan untuk menganalisis data. Field yang digunakan dalam melakukan analisis data adalah id, nama, alamat, agama, gender, handphone dan alamat. Field di atas dapat digunakan untuk menampung sumber data atau informasi yang dimiliki oleh Subclass db_pegawai. 
[3] S. Bagui, "Mapping Generalizations and Specializations and Categories to Relational Databases," Handbook of Research on Innovations in Database Technologies and Applications: Current and Future Trends, pp. 2009-2011, 2009.

[4] H. B. Zghal, S. Faïz, and H. Ben Ghézala, "CASME : A CASE Tool for Spatial Data Marts Design and Generation," International Journal of Cooperative Information Systems., pp. 111, 2003.

[5] Y. Pitarch, C. Favre, A. Laurent, and P. Poncelet, "Context-aware generalization for cube measures," Proceedings of the ACM 13th international workshop on Data warehousing and OLAP (DOLAP'10), p. 99, 2010.

[6] R. Liu, K. Koedinger, and E. a Mclaughlin, "Interpreting Model Discovery and Testing Generalization to a New Dataset," Proceedings of the Seventh International Conference on Educational Data Mining, pp. 107-113, 2014.

[7] M. Golfarelli and S. Rizzi, Data warehouse design: Modern principles and methodologies. McGraw-Hill, Inc., 2009.

[8] A. Bonifati, F. Cattaneo, S. Ceri, A. Fuggetta, and S. Paraboschi, "Designing data marts for data warehouses," ACM Transactions on Software Engineering and Methodology (TOSEM), vol. 10, no. 4, pp. 452-483, 2001.

[9] J. Eder and S. Kanzian, "Logical Design of Generalizations in Object-Relational Databases," in East European Conference - Advances in Databases and Information Systems, 2004, vol. 8th. 